\title{
Frugal Science: The Science for all
}

\author{
Pratik Tawade ${ }^{1}$ \\ ${ }^{1}$ IIT Madras
}

September 14, 2020

\section{Science is not just about knowing but also about experiencing.}

Today with the boon of technological advancement we have easy access to information and knowledge which is merely a click away with the advent of technological transformation. Science is largely about learning and it majorly comes through the experience. So, it's more important how you can make the experience of science more accessible to a lot of people around the world.

The actual experience of science is utilizing scientific tools to make your own discoveries. Prof. Manu Prakash at Stanford University ${ }^{1}$ is in a quest of how can we make scientific tools that are so affordable, which are like buying a pencil from a shop, So what it would mean if a scientific tool is as accessible as pencil? What you would actually do, would you sketch with it or would you write a poetry with it, what exactly is the end of that for science? This really can be done across different fields by making scientific devices and tools for all. So how do you make the microscopic world easily visible, it's just around you but most people haven't actually seen it. What a feeling of wonder it would be for all the people to zoom into that invisible world which we are part of.

Frugal Science which came out as a philosophy is now an innovative research field. Frugal Science is a type of research focusing on the development of scientific tools that are far cheaper and more accessible to the average person ${ }^{2}$. Accessibility is a big challenge that science is faceing. The day is not far when we can have devices for point of care applications in our pocket, the devices which are versatile and robust. We can have diagnostics of deadly infectious diseases in the field with simple and easy devices without the sophisticated instruments and expertise. Improve the quality of treatment and also decrease the cost so that broad community of people can benefit. ${ }^{3}$

Science doesn't always have to be costly. This way people can experience the science and can make them more curious, have them discover this new world and interpret it in their own way. With frugal science we can have designers and inventors at every home, you just need nourish your curiousity as we know, "Curiosity is the mother of inventions". With accessibility to frugal tools people can unleash and discover the world and experience the science for themselves. Also, this can lead to transformation in global health solutions and making healthcare accessible to the most remote parts of the world and making it more affordable. There are plenty of problems around us which are in urgent need to be addressed but with simple solutions.

We need many frugal scientist for together making this world a better place to live.

\section{Be Crazy Be Curious!!}

\section{References}

1.PRAKASH LAB.

2.Frugal innovation. 
3.Frugal science. 